\title{
ИСТОРИЯ РАЗВИТИЯ УГОЛОВНО-ПРАВОВОЙ ОХРАНЫ ОБЪЕКТОВ ПАТЕНТНЫХ ПРАВ В ДОРЕВОЛЮЦИОННОЙ РОССИИ
}

\author{
Гантемиров Казбек Рустамович \\ Аспирант, ФГБОУ ВО Кубанский государственный \\ университет
}

THE HISTORY OF THE DEVELOPMENT

OF CRIMINAL LAW PROTECTION

OF OBJECTS OF PATENT RIGHTS

IN PRE-REVOLUTIONARY RUSSIA

K. Gantemirov

Summary. Purpose: to investigate the history of the establishment by the legislator of criminal protection of inventions and industrial designs in pre-revolutionary Russia in the middle of the XIX-early XX centuries.

Methods: the general method of cognition in the form of a dialectical approach, general scientific methods of cognition in the form of inductions, deduction, abstraction, as well as private scientific methods in the form of a statistical method.

Results: criminal legal protection of objects of patent rights in prerevolutionary Russia arose as a result of an increase in the number of granting privileges for inventions several times by the time of the adoption of the Code on Criminal and Correctional Punishments of 1845. In this document, as amended in 1866, when the legislator established the protection of industrial designs, scientists noted the commonality of copyright and patent rights, the commonality of committing crimes against objects of patent and copyright. The legislator also established a civil procedural procedure for the protection of patent rights instead of an administrative procedure. The Criminal Code of the 1909 edition officially established the previously mentioned community of copyright and patent rights, fixing crimes against the relevant objects in one chapter.

Conclusions: the criminal legal protection of objects of patent rights in Russia actually arose in the Regulations on Criminal and Correctional Punishments of 1845 , as amended in 1866, when the legislator established such protection of industrial designs as non-utilitarian, creative results of the inventors ' activities. Officially, the previously mentioned protection was established in the Criminal Code at the beginning of the XX century, when the legislator fixed criminal liability for committing crimes against objects of copyright and patent rights in one chapter.

Keywords: objects of patent rights, inventions, industrial designs, counterfeiting, the Code of Criminal and Correctional Punishments, the Criminal Code.

Аннотация. Цель: исследовать историю установления законодателем уголовно-правовой охраны изобретений и промышленных образцов в дореволюционной России середины XIX — начала XX веков.

Методы: всеобщий метод познания в виде диалектического подхода, общенаучные методы познания в виде индукций, дедукции, абстрагирование, а также частнонаучными методами в виде статистического метода.

Результаты: уголовно-правовая охрана объектов патентных прав в дореволюционной России возникла в результате увеличения числа выдачи привилегий на изобретения в несколько раз к моменту принятия Уложения 0 наказаниях уголовных и исправительных 1845 года. В данном документе в редакции 1866 года, когда законодатель установил защиту промышленных образцов, ученые отмечали общность авторских и патентных прав, общность совершения преступлений против объектов патентных и авторских прав. Также законодатель установил гражданский процессуальный порядок защиты патентных прав вместо административного порядка. Уголовное уложение издания 1909 года официально установил ранее указанную общность авторских и патентных прав, закрепив преступления против соответствующих объектов в одну главу.

Выводы: уголовно-правовая охрана объектов патентных прав в России фактически возникла в Уложений о наказаниях уголовных и исправительных 1845 года издания в редакции 1866 года, когда законодатель установил подобную охрану промышленных образцов как неутилитарных, творческих результатов деятельности изобретателей. Официально ранее указанная охрана установлена в Уголовном уложении в начале XX века, когда законодатель закрепил в одну главу уголовную ответственность за совершения преступлений против объектов авторских и патентных прав.

Ключевые слова: объекты патентных прав, изобретения, промышленные образцы, контрафакция, Уложение о наказаниях уголовных и исправительных, Уголовное уложение. 


\section{Ввемение}

3 аконодатель впервые установил уголовно-правовую охрану изобретений в Уложении о наказаниях уголовных и исправительных 1845 года, а также промышленные образцы в данном документе в редакции 1866 года. Однако в то время еще не возникло патентное право, которое бы предполагало понимание изобретателей как авторов, его изобретений как результатов творческой деятельности, а также наличие у патентообладателей имущественных и личных неимущественных прав. Соответственно, объекты патентных прав фактически получают уголовно-правовую охрану в момент принятия редакции 1866 года к Уложению о наказаниях уголовных и исправительных. Официально они получают указанную охрану в момент принятия Уголовного уложения в начале XX века.

\section{Цель работы}

Исследование истории зарождения и развития уголовно-правовой охраны изобретений и промышленных образцов в дореволюционной России середины $\mathrm{XIX}$ - начала XX веков.

Задачи исследования включают в себя:

- определение начало возникновения уголовно-правовой охраны объектов патентного права,

- изучение процесс его развития до отмены положений дореволюционного законодательства советским правительством.

\section{Материалы и метолы}

Для осуществления исследований изучались нормы уголовного законодательства дореволюционной России середины XIX - начала XX веков. Изучались положения дореволюционных нормативных правовых актов, которые устанавливали общие положения об объектах патентных прав. Также изучались труды дореволюционных юристов, современных ученых, которые затрагивали уголовно-правовую охрану изобретений и промышленных образцов в указанном периоде. В качестве методов исследования были применены всеобщий метод познания в виде диалектического подхода, общенаучные методы познания в виде индукций, дедукции, абстрагирование, а также частнонаучными методами в виде статистического метода.

\section{^итературный обзор}

Уголовно-правовая охрана объектов патентных прав в России имеет начало в середине XIX века. 15 августа 1845 году законодатель принял «Высочайше утвержденное Уложение о Наказаниях Уголовных и Ис- правительных» [2, с. 599]. Данный закон впервые установил уголовно-правовую охрану привилегий на изобретения, а также промышленных образцов в виде фабричных рисунков и моделей в редакции 1866 года.

Нормы уголовного закона действовали на основе норм Высочайше утвержденного Положения о привилегиях от 22 ноября 1833 года [1, с. 692]. Документ повторял с некоторыми уточнениями и изменениями нормы Манифеста «О привилегиях на разные изобретения и открытия в художествах и ремеслах» от 17 июня 1812 года [6, с. 355]. Оба документа указывали сущность подделки и право лица, которое имело привилегию, преследовать ее и требовать возмещения убытков.

Ко времени действия Положения 1833 года законодатель принял том 15 «Свод законов уголовных» из Свода законов Российской Империи. Указанный документ не содержал нормы об уголовной ответственности за преступления в отношении объектов патентных прав. Полагаем, законодатель не установил уголовную ответственность по следующей причине. За период 1813-1832 годов, согласно подсчетам Аэра А. с изменениями Ревинского Д.О., государство выдало 72 привилегий [9, с. 347], максимальное и минимальное значения за один год составляли 0 и 10 соответственно, среднее арифметическое значение - 3-4 привилегий в год. Данная статистика демонстрирует отсутствие для законодателя необходимости установления в то время уголовной ответственности за нарушения привилегий на изобретения.

До 1845 года лица, которые получили привилегии, могли преследовать нарушителей данного документа путем подачи жалобы в специально уполномоченные органы. Пиленко А.А. полагал, что в то время привилегии были факультативными, то есть государство их выдавало как акты милости государя [7, с. 194]. Соответственно, указанные органы рассматривали и разрешали дела о нарушении привилегий на изобретение в порядке административного процесса. Впоследствии законодатель установил нормы об уголовной ответственности за нарушение чужой привилегии на изобретения в Уложении о наказаниях 1845 года в разделе «О преступлениях и проступках против общественного благоустройства и благочиния», в главе «О нарушении Уставов фабричной, заводской и ремесленной промышленности» и в отделении «О нарушении Уставов фабричной и заводской промышленности». То есть он следовал представлению об изобретениях как явлению, которая свойственна обществу, не личности. А значит, они представляли из себя часть административного правового регулирования, не гражданского.

С 1830-х годах в России фабричное производство на основе применения механических двигателей на- 
чинает распространение. И промышленный переворот завершает свое действие в 1880-е годы, когда фабричное производство стало преобладать в основных отраслях обрабатывающей промышленности. Данные обстоятельства привели к укрупнению промышленных предприятий [12, с. 56-57].

После принятия Положения о привилегий 1833 года до принятия Уложения о наказаниях 1845 года количество выдачи привилегий увеличилось. То есть в период 1833-1845 годов оно составляло всего 230 привилегий [9, с. 347]. Максимальное и минимальное значения за один год составляли 2 и 30 соответственно, среднее арифметическое значение - около 19 привилегий в год. Как можем заметить, количество выданных привилегий увеличилось в среднем значении в 5-6 раз, в абсолютном значении почти в 3 раза. Общественное отношение в сфере выдачи привилегий на изобретение значительно возросло как область нормативного правового регулирования до такого уровня развития, когда общество и государства будут осознавать необходимость уголовно-правовой охраны этих отношений.

Аэр А. отмечала, государство так следило за выдачей привилегий потому, что вопрос патентования в России по своему происхождению был экономическим (тогда как на Западе изначально стоял вопрос прав человека), а экономика традиционно подлежала в нашей стране постоянному наблюдению и вмешательству со стороны государства $[15$, с. 34-35].

Поэтому законодатель имел объективные причины установления в Уложении о наказаниях 1845 года уголовно-правовую охрану изобретений. Данные факторы исходили как от потребностей общества, так и от потребностей государства.

Как мы говорили ранее, законодатель отнес преступление против изобретений в части уголовного закона, которые устанавливали охрану в сфере промышленности, на уровне общества. Тогда государство воспринимало изобретения как собственность в Манифесте 1812 года и в Положении о привилегиях 1833 года, прямо указывая такой взгляд. То есть тогда он осознавал лишь материальное содержание изобретения, как собственности, не воспринимал их результаты творчества изобретателей. А значит, устанавливал защиту имущественных прав лиц, которые получили привилегии на изобретения.

Вместе со статьей о нарушении чужой привилегии на изобретения законодатель расположил статьи о посягательствах на товарные знаки и на секреты производства. Вероятно, он имел осознание о наличии интеллектуального содержания указанных объектов преступлений в виде промышленной собственности абстрактно. Ведь в отличие от преступлений против авторских прав, которых он отнес к уголовно-правовой охране на уровне личности, он не выделил специальное отделение для преступлений против промышленной собственности. Однако позднее дореволюционные юристы относили указанные преступления в разные группы преступлений, несмотря на такое расположение законодателем статей об указанных преступлениях. По крайней мере можем полагать, что юристы того времени имели однозначное мнение, что преступления против изобретений и промышленных образцов входили в «присвоении прав промышленной собственности» [4, с. 434], а также включали их в промышленную собственность [14, с. 343].

Законодатель установил преступление против привилегий на изобретения в статье 1788 «Уложения о наказаниях уголовных и исправительных» 1845 года в первой редакции [2, с. 917]. Норма устанавливала ответственность за нарушение чужой привилегий на изобретения под угрозой применения штрафа в размере 100-300 рублей и возмещение убытков за понесенный ущерб от совершения преступления. Авторы уголовного закона составил диспозицию в абстрактной, не свойственной его юридической технике казуистичной форме. Полагаем, он поступил таким образом ввиду ранее указанной причины об осознании им интеллектуального содержания изобретений. Благодаря такого написания диспозиции норм законодатель дал некоторую свободу лицам преследовать нарушителей привилегий. Вследствие этого норма менялась одновременно с эволюцией понимания изобретателей как авторов своих результатов творческой деятельности. Ведь изначально преступление предполагало посягательство именно на чужую привилегию [4, с. 437], а также предполагало совершение подделки [4, с. 438].

Однако привилегии на изобретения предоставляли их обладателям исключительное право производить, употреблять, продавать, дарить, в залог и на наследниках отдавать свое изобретение [8, с. 842]. То есть эти права было возможно нарушить путём совершения подделки, употребления и распространения изобретений. Данные действия входят в понятие контрафакции [7, с. 603], которая предполагает посягательства на авторские права [11, с. 99]. Вероятно, практика защиты прав уголовно-правовым порядком по жалобе обладателей привилегий повлияли на изменение содержания признаков объективной характеристики преступлений против привилегий на изобретения.

Предполагаем, именно в редакции 1866 года Уложение о наказаниях 1845 года приняло данные изменения, хоть законодатель не изменил норму статьи 
о нарушении привилегий на изобретение, только поменял номер статьи 1353 указанного документа, который останется до конца дореволюционного периода.

В данной редакции законодатель установил уголовную ответственность за посягательства на промышленные образцы в виде фабричных рисунков и моделей в статьях 1356 и 1357 в результате принятия Положение о праве собственности на фабричные рисунки и модели в 1864 году, согласно которому законодатель признавал указанные объекты как результаты деятельности изобретателя. Фабричные рисунки и модели не предполагают выполнение утилитарных задач, не несут практической ценности в отличие от изобретений. Так что государство установило правовое регулирование и уголовно-правовую охрану объекта промышленной собственности, которое содержит интеллектуальную природу, не материальную. То есть законодатель косвенно признало изобретателей и их изобретений как авторов и их произведений соответственно. А значит, стал понимать данную сферу как части правового регулирования на уровне личности, а также понимать важность защиты личных неимущественных прав изобретателей. И по крайней мере он косвенно установил общность авторского и патентного прав, которая является условием возникновения последнего.

Вдобавок, к 1860-1870-е годы законодатель принимал множество актов об изменении нормативного правового регулирования и осуществления сферы привилегии на изобретения. Среди этих актов входит Высочайше утвержденное мнение «Об изменении порядка делопроизводства по выдаче привилегий на новые открытия и изобретения» 30 марта 1870 года [3, с. 339-340]. С точки зрения Пиленко А.А., указанный документ положил началу патентному праву в России, ведь он превращает выдачу привилегий из свободной законодательной функции в связанную подзаконную деятельность административного органа [7, с. 200]. Иными словами, переносило изобретения из сферы административного правового регулирования в гражданское.

Более того, ученые-юристы к тому времени высказывали мысль об общности авторских и патентных прав. Например, Спасович В.Д. в 1865 году утверждал «авторские права на изобретение или произведение, ученое или артистическое» [11, с. 99]. Также Неклюдов Н.А. в 1878 году утверждал, что право промышленной собственности и право авторской собственности имеют те же основы [4, с. 434].

Как видим, процесс формирования патентного права протекало не сразу в виде одного акта, а продолжительно в результате существований нескольких условий в научной, законодательной и общественной сферах. Таким образом, полагаем, именно Уложение о наказаниях в редакции 1866 года устанавливало уголовно-правовую охрану изобретений и промышленных образцов как объектов непосредственно патентного права, которое возникла в результате принятия Положения о праве собственности на фабричные рисунки и модели в 1864 году. А, следовательно, посягательства на изобретения и на промышленные образцы в статьях 1353 и 1357 Уложения о наказаниях редакции 1866 года соответственно затрагивали имущественные и личные неимущественные права.

Законодатель официально признал общность авторского и патентного права как объектов уголовно-правовой охраны в Уголовном уложении в неофициальном издании 1903 года, которое затем примет в 1909 году с некоторыми изменениями. Он расположил преступления против указанных прав в одну главу. В рамках посягательств на изобретения он добавил статью 622 указанного уголовного акта. Данная норма устанавливала уголовную ответственность торговца за распространение изобретений и произведений [10, с. 312]. Статья 621 Уголовного уложения представляет больший интерес. Она устанавливала уголовную ответственность за самовольное пользование чужой привилегией на изобретение или чужим правом на воспроизведение заводских, фабричных или ремесленных модели и рисунка под угрозой наказания в виде ареста или денежной пеней не свыше 500 рублей [5, с. 202]. Как и статья 620 о защите авторских прав, статья 621 указывал схожую объективную сторону в виде «самовольного пользования ... привилегией на изобретение или чужим правом на воспроизведение ... модели и рисунка» [5, с. 202]. Более того, Фон-Резон А.К. отмечал, норма статьи 621 Уголовного уложения представлял из себя норма статьи 1353 о нарушении привилегии на изобретение, а также норма статьи 1357 о самовольном воспроизведении фабричных рисунков и моделей [13, с. 277]. А значит, статьи 1353 и 1357 Уложения о наказаниях защищали имущественные и личные неимущественные права изобретателей в том виде, которых законодатель изложил в редакции 1866 года указанного уголовного закона. Соответственно, Уголовное уложение издания 1909 года только официально подтвердило установленные ранее уголовно-правовую охрану объектов непосредственно патентных прав в Уложении о наказаниях редакции 1866 года.

Формально законодатель установил уголовно-правовую охрану изобретений в 1845 году, вносил в ней изменения в виде добавления промышленных образцов в качестве объектов охраны в редакции 1866 году и принятия Уголовного уложения издания 1909 года, которое добавила один состав преступления о распространении указанных объектов торговцами. 


\section{Результаты}

Непосредственно процесс развития уголовно-правовой охраны объектов патентного права в дореволюционной России протекал в три этапа.

Первый этап проходил с принятием «Уложения о наказаниях уголовных и исправительных» 1845 года по принятии его новой редакции в 1866 году. На этом этапе законодатель установил охрану только изобретений, имущественных прав изобретателя, которые регулируются нормами административно-правового характера. При этом уже в то время ученые отождествляли авторское и патентное права в части их сущности.

Второй этап проходил с момента принятия редакции 1866 года «Уложения о наказаниях уголовных и исправительных» по принятия Уголовного уложения в начале XX века. На этом этапе законодатель на основе принятых им нормативных правовых актов, а также с учетом научных исследований ученых-юристов и результатов практики рассмотрения уголовных дел о нарушении привилегий на изобретения установил уголовно-правовую охрану промышленных образцов. Законодатель еще официально не признал общность авторских и патентных прав, однако путем установления охраны указанных образцов он признал отсутствие утилитаризма в деятельности изобретателя, установив в ней творчество. Тем самым он косвенно признавал наличие и защиту имущественных и лично неимущественных прав изобретателя.

Третий этап начинается с момента принятия Уголовного уложения по отмены положений дореволюционного законодательства советским правительством. Законодатель официально установил общность авторских и патентных прав, а также уголовно-правовую защиту имущественных и личных неимущественных прав изобретателей. Поэтому уголовно-правая охрана объектов именно патентного права возникла в «Уложении о наказаниях уголовных и исправительных» редакции 1866 года.
Таким образом, уголовно-правовая охрана объектов патентных прав, которые предполагали понимание изобретателей как авторов, его изобретений как результатов творческой деятельности, а также наличие у патентообладателей имущественных и личных неимущественных прав, фактически берет свое начало с момента принятия Уложения о наказаниях уголовных и исправительных 1845 года издания в редакции 1866 года. В то время действовал принятый в 1864 году Положение о праве собственности на фабричные рисунки и модели, которое признавал указанные объекты результатами деятельности изобретателя как и изобретения. Официально законодатель признал данное положение путем принятия Уголовного уложения в начале XX века, закрепив статьи о составах преступлений против авторских и патентных прав в одну главу, посвященной охране указанных прав.

\section{Обсужление}

Нами было выявлено, что исследуемая тема мало освещена учеными, которые составляли научные работы по теме уголовно-правовой охраны объектов патентных прав. Не было выявлено каких-либо результатов исследований по указанной теме среди современных ученых в области уголовного права. Данная тема изучена дореволюционными юристами в рамках непосредственно патентного права, среди которых акцентировал внимание на изучение данной темы Пиленко А.А.Он полагал, что само патентное право возникло в результате принятия мнения Государственного Совета «Об изменении порядка делопроизводства по выдаче привилегий на новые открытия и изобретения» от 30 марта 1870 года, обратив внимание на процессуальные начала возникновения патентного права. Данное положение соответствует результатам проведенного нами исследования, однако мы обратили внимание на материальный начала возникновения патентного права в принятии Положение о праве собственности на фабричные рисунки и модели в 1864 году.

\section{ЛИТЕРАТУРА}

1. Высочайше утвержденное «Положение о привилегиях» от 22 ноября 1833 года // Полное Собрание законов Российской Империи. Собрание второе. СПб., 1834. Т. 8. № 6588.

2. Высочайше утвержденное «Уложение о Наказаниях Уголовных и Исправительных» от 15 августа 1845 года // Полное Собрание законов Российской Империи. Собрание второе. СПб., 1846. Т. 20. № 19283

3. Высочайше утвержденное мнение Государственного Совета «0б изменении порядка делопроизводства по выдаче привилегий на новые открытия и изобретения» от 30 марта 1870 года // Полное Собрание законов Российской Империи. Собрание второе. СПб., 1874. Т. 45 , № 48202.

4. Неклюдов Н.А. Руководство к особенности части русского уголовного права: практическое пособие Т. 2. Преступления и проступки против собственности. СПб.: Типография В.П. Воленса. 1876. 757 с.

5. Новое Уголовное Уложение, Высочайше утвержденное 22 марта 1903 года. СПб.: Издание Каменноостровского Юридического Книжного Магазина В.П. Анисимова, 1903. 
6. Манифест «0 привилегиях на разные изобретения и открытия в художествах и ремеслах» от 17 июня 1812 года // Полное Собрание законов Российской Империи. Собрание первое. СПб., 1830. Т. 32. № 25143.

7. Пиленко А.А. Право изобретателя. М.: Статут, 2005. 779 с.

8. Привилегия, выданная Коллежскому Советнику Давыдову на изобретенный им способ извлечения сока из свекловицы от 28 августа 1834 года // Полное Собрание законов Российской Империи. Собрание второе. СПб., 1835. Т. 9. № 7367.

9. Свод законов Российской Империи. Т. 15. Ч. І: Уложение о наказаниях уголовных и исправительных; Ч. ІІ: Уголовное уложение: (статьи, введенные в действие). Петроград: Государственная типография, 1916.

10. Спасович В.Д. Права авторские и контрафакция. СПб.: М.0. Вольф, 1865. 106 с.

11. Ревинский Д.О. Патентование изобретений в России (1812-1870 гг.) // Экономический ежегодник. 2002. Т. 2001. С. 339-376.

12. Успенский В.А. Очерк истории предпринимательства в России // Мир новой экономики. 2013. № 1. С. 55-61.

13. Фон-Резон А.К. Уголовное уложение (краткое изложение главных положений его) в сопоставлении его с действующим правом. СПб.: Издание Я.А. Канторовича, 1903. $341 \mathrm{c}$.

14. Шершеневич Г.Ф. Курс гражданского права. Тула: Автограф, 2001. 720 c.

15. Aer A. Patents in Imperial Russia: A History of the Russian Institution of Inventions on Privileges under the Old Regime. Helsinki, 1995. p. 231.

(ㄷ Гантемиров Казбек Рустамович ( kazbek.27@yandex.ru ).

Журнал «Современная наука: актуальные проблемы теории и практики»

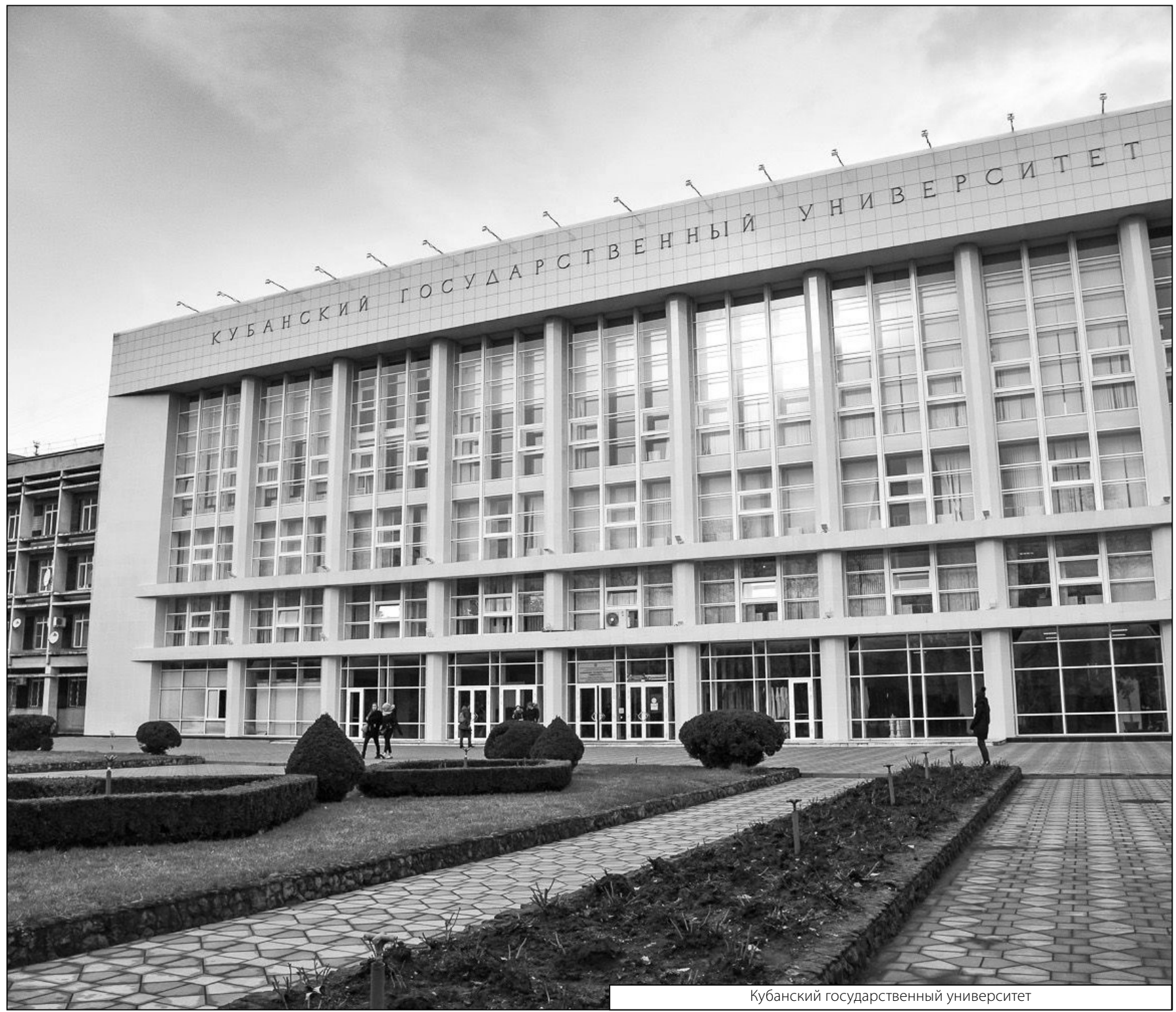

